\title{
O Ensino da Anatomia: Integração do Corpo Humano e Meio Ambiente
}

\author{
Teaching of Anatomy: Integration of the \\ Human Body and the Environment
}

\author{
Célia Cristina Fornaziero ${ }^{I}$ \\ Pedro Alejandro Gordan ${ }^{I}$ \\ Maria Aparecida Vivan de Carvalho ${ }^{I}$ \\ José Carlos Araujo \\ Juarez Cezar Borges de Aquino
}

\section{PALAVRAS-CHAVE \\ - Anatomia. \\ - Educação em Saúde. \\ - Metodologia.}

Artigo recebido em: 13/07/2009

Rencaminhado em: 04/09/2009

Aprovado em: 14/09/2009
RESUMO

A constante evolução da tecnologia educacional faz emergir a necessidade de suscitar reflexões sobre a prática pedagógica, e este processo dever ser discutido entre educadores e profissionais da saúde. Neste contexto, o ensino da Anatomia Humana precisa ser repensado a fim de corresponder às expectativas deste novo e atual momento. Na tentativa de apresentar alternativas de solução, implantamos um projeto de extensão na Universidade Estadual de Londrina que ensina Anatomia Humana promovendo uma integração das relações entre corpo humano e meio ambiente. Nele, os participantes desenvolveram atividades interdisciplinares de pesquisa-ação com o emprego de diferentes métodos de ensino-aprendizagem dialogados, com alunos do ensino fundamental de uma escola pública. Os resultados obtidos foram positivos no sentido de aliar o conhecimento de uma ciência básica como a Anatomia ao conhecimento ambiental, num modelo de processo ensino-aprendizagem diferenciado. Acima de tudo, a formação educacional se elabora por meio de um trabalho de flexibilidade crítica e de construção contínua de identidade entre o professor e o grupo de estudantes, considerando a realidade social da população regional.

\section{ABSTRACT}

Constant evolution in educational technology has raised the need to reflect on teaching practice and to discuss this practice among educators and health professionals. In this context, the teaching of $\mathrm{Hu}$ man Anatomy needs to be reviewed in order to meet these new expectations. In the attempt to present alternative solutions, we implemented an extension project under the State University in Londrina, Paraná, Brazil, teaching Human Anatomy from the perspective of integrating the relations between the human body and the environment. Course participants conducted interdisciplinary action-based research activities using different dialogical teaching-learning methods with public primary school students. The results were positive in the sense that the approach combined a basic science like Anatomy with environmental knowledge in a unique teaching-learning model. In particular, the educational process is elaborated through critical flexibility and on-going development of identity between the teacher and students, considering the regional population's social reality. 


\section{INTRODUÇÃO}

Com as frequentes vertentes transformadoras observadas na conjuntura mundial, a universidade tem, hoje, o dever de proporcionar ao estudante uma formação ímpar para que ele possa almejar tornar-se um profissional livre da visão unilateral que absolutiza valores e crenças dos grupos sociais, com um perfil crítico e criativo frente às distintas situações do cotidiano, com bom domínio da tecnologia em vigência, de dinâmica em grupo e destreza na comunicação ${ }^{1}$.

Estas características requerem uma pessoa com espírito questionador, capaz de iniciativas inovadoras para criar soluções eficazes em questões multidimensionais. Felizmente, avanços essenciais no campo da psicologia cognitiva abrem espaço para novas formas de compreensão do processo ensino-aprendizagem, gerando perspectivas para a formulação de abordagens educacionais sincronizadas com a contemporaneidade ${ }^{2}$.

A constante evolução da tecnologia educacional faz emergir a necessidade de apreensão, clarificação e possíveis adaptações dos métodos de ensino-aprendizagem. Para tanto, acredita-se haver possibilidade de modificações das práticas pedagógicas, visto que as mudanças já estão inseridas no dia a dia dos estudantes e que o processo ensino-aprendizagem deve ser condizente com a realidade que o acadêmico vivencia em sua rotina. Este processo deve ser largamente discutido entre os professores para que se apliquem propostas pedagógicas coerentes, instigando a transformação do desempenho dos sujeitos em sala de aula.

Está florescendo uma oportunidade singular de analisar o processo ensino-aprendizagem da ciência Anatomia Humana, visto que professores da Universidade Estadual de Londrina têm se posicionado de forma receptiva às transformações e às avaliações que contribuem para o aprimoramento metodológico e para a integração entre academia e comunidade. Tem-se oportunizado um programa de ensino reflexivo e crítico, voltado à realidade social de nosso país, especificamente à região norte do Paraná, visto que estudantes de vários cursos desta instituição estão descobrindo uma nova forma de aprender Anatomia.

Atualmente, é inadmissível que a educação se baseie em princípios do senso comum, já que tem como objetivo formar consciências críticas, capazes de compreender, propor e agir em função de novas perspectivas de vida. Por este motivo, é preciso que tanto os educadores quanto a sociedade venham a filosofar e ultrapassar os limites do senso comum como entendimento e orientação para o planejamento de nossa prática pedagógica ${ }^{3}$.

Os projetos curriculares, as disciplinas, os conteúdos, a organização do ensino, as condutas de professores e estudantes não devem ser contemplados simplesmente como questões técnicas e neutras, à margem das ideologias e daquilo que ocorre em outras dimensões da sociedade, como a econômica, cultural e política. Parte significativa das decisões asseguradas no âmbito educacional está condicionada por outros setores da sociedade e atinge seu significado a partir da análise que leva em conta essa interpretação ${ }^{4}$.

O primeiro passo para que o profissional da saúde inicie seu caminhar na área educacional é compreender a pedagogia de hoje, sendo necessária uma releitura reflexiva do ensino com o intuito de despertar a consciência sobre o que o planejamento pedagógico abrange, já que este não se restringe à imposição de ideias embasadas em conhecimento próprio, mas abrange um posicionamento de autoavaliação por parte do educador em relação ao exercício docente. O ensino da Anatomia Humana, por sua vez, precisa ser repensado a fim de corresponder às expectativas deste novo contexto educacional.

A sucessão de transformações observadas no desdobramento de cursos da área de saúde reflete o mundo contemporâneo, coalhado de incertezas, complexidades, exigências e globalização. Neste sentido, os desafios que surgem na sociedade e no sistema educacional conduzem o educador a uma responsabilidade maior quanto à direção do ensino e da aprendizagem, por seu posicionamento de mediador entre o particular do estudante e os valores da coletividade.

Desta maneira, o docente adquire papel essencial nos processos intrinsecamente ligados à teoria e à ciência da educação e do ensino, os quais envolvem procedimentos de planejamento, desenvolvimento de ações e avaliação. A aplicação de processos pedagógicos em sala de aula precisa estar explicitamente documentada, já que requer atenção diária sobre sua gestão ${ }^{5}$.

Os procedimentos mencionados abrangem desde a resolução imediata de pequenas necessidades até a verificação de possibilidade de programação e adaptação de atividades, organização de rotinas de ações, do tempo, do material, do espaço, ou ainda a verificação de conhecimentos prévios, bem como avaliação com consistência teórica e prática. Estes princípios pedagógicos se referem ao jeito de pensar e de fazer a educação em seus elementos mais gerais e essenciais, especialmente no que se refere à reflexão metodológica acerca de processos educativos ${ }^{5}$.

A prática pedagógica se encontra em um processo acelerado e irreversível de transformações técnicas e científicas, sendo indiscutível a necessidade de um planejamento minucioso para que a atividade educacional não esteja embasada em improvisos. O processo de construção curricular exige um trabalho multidimensional, em que os saberes estejam integrados. A arte de planejar conduz os docentes a uma reflexão mais profunda sobre sua prática pedagógica ${ }^{6}$.

O planejamento vislumbra promover alterações que conduzem à tomada de decisões em bases sólidas, interrompendo 
a repercussão de improvisos bloqueadores da criatividade e do desenvolvimento coletivo. A preparação das aulas, independentemente da metodologia aplicada, cria condições para que o docente se sinta seguro quanto ao seu desempenho e possibilita uma sequência lógica na formulação de conceitos, racionalizando a ação educativa.

Desta maneira, o professor será capaz de contribuir para formar cidadãos conscientes e participativos, prontos para usufruir o avanço técnico-científico necessário à inclusão social, como garantia da educação das diferenças e ampliação da justiça social. A escolha de um método de ensino adequado é essencial para o alcance desses propósitos, considerando que cada técnica tem suas características, fundamentos, aplicações e consequências ${ }^{6}$.

No entanto, o estudante e o professor, e não o currículo, são elementos cruciais em um programa educacional fundamentalmente em três metodologias vigentes no ensino da área de saúde: currículo centrado em disciplinas tradicionais, ensino orientado por sistemas orgânicos e aprendizagem baseada em problemas ${ }^{7}$. Essas três formas podem ser enriquecidas com projetos de extensão e de pesquisa.

É primordial prosseguir no sentido de ampliar as opções metodológicas, mas é inquestionável que o objetivo final é oferecer ao estudante a chance de construir sua realidade e criar significados de forma digna e comprometida com a qualidade de vida e de saúde da população, submetendo-se aos princípios éticos e morais de determinada sociedade e compartilhando sua visão de mundo.

Perante a realidade social das instituições médicas, é possível constatar que mudanças curriculares geralmente implicam tentativas de condensar o programa proposto ao curso, especialmente quando se trata das ciências básicas (Fisiologia, Anatomia, Farmacologia, Biologia, Histologia), simplesmente eliminando tópicos considerados de relevância secundária. Desta forma, é preciso resistir para que a Anatomia Humana continue num patamar de importância na educação médica, subsidiando e reforçando os estudos da área básica ${ }^{8}$.

Portanto, acreditando que um dos principais objetivos do ensino é lutar contra a artificialidade da escola e aproximá-la da realidade da vida, é preciso, cada vez mais, orientar procedimentos e conferir motivação, permitindo que o estudante participe de maneira responsável do seu processo de aprendizagem 9 .

Diante do exposto, somos instigados a considerar a temática sobre o processo ensino-aprendizagem da Anatomia Humana, ventilando a suposição de que sua recente contribuição ao programa curricular dos cursos da área de saúde pode não estar correspondendo às expectativas deste novo e atual momento. Na tentativa de apresentar alternativas de solução, construímos o projeto de extensão "Contribuição à construção da cidadania: integração da dimensão ambiental na educação escolar rural", em que os participantes planejaram e desenvolveram atividades com alunos de todas as turmas do ensino fundamental de uma escola pública da área rural da cidade de Londrina, no Paraná.

Após considerar o resgate histórico do tema, por meio da revisão de literatura, associada à experiência profissional arquitetada na realidade vivenciada pelos integrantes do Departamento de Anatomia da Universidade Estadual de Londrina, bem como a vontade intrínseca de buscar respostas para questionamento tão inquietante que aflige a prática docente, $\mathrm{o}$ objetivo proposto para o estudo foi avaliar a aplicação de uma abordagem interdisciplinar de conteúdos relativos à Anatomia e ao meio ambiente, a fim de contribuir com uma visão crítica e criativa dos estudantes e aproximar a realidade dos ensinos fundamental e superior.

\section{METODOLOGIA}

Foram utilizados princípios da pesquisa-ação, com a conjugação de diferentes situações de ensino-aprendizado dialogadas, envolvendo métodos alternados: intuitivo (imagens construídas; construção mental), ativo (saídas a campo) e construtivista (integração de arte e educação). Os estudantes universitários envolvidos no projeto de extensão desenvolveram atividades que contemplaram:

— estudo de órgãos do corpo humano; orientação sobre os cuidados com o corpo humano e as relações com o meio ambiente, com foco na educação ambiental, onde é possível destacar a importância do cuidar do meio ambiente (conservação, preservação); as atividades foram realizadas por meio de palestras, discussões de grupo, entrega de textos, fixação de cartazes, exposição teórico-prática de peças anatômicas normais e alteradas por diversas patologias, sempre com ênfase nas questões ambientais;

- execução de atividades a fim de promovera sensibilização e a incorporação de modos de olhar e de agir diferenciados para o próprio corpo e para o meio ambiente, por meio de trilha interpretativa, concurso de desenhos, confecção de frases, peças teatrais e abraços simbólicos, entre outras;

- planejamento e execução de oficinas, com participação da direção da escola, professores e funcionários.

A cada semana, as atividades foram intercaladas, com exposição teórico-prática de peças anatômicas, desenvolvimento de uma peça teatral, realização de um percurso (trilha interpretativa) até o córrego vizinho à escola, com abraço simbólico de árvores, realização de um concurso de redação, análise de um texto ou música para interpretação. Ao mesmo tempo em que trabalhamos com as crianças, foram realizadas quatro ofi- 
cinas de sensibilização para os professores e funcionários da escola sobre a percepção das relações do corpo humano e meio ambiente, e as possibilidades de associar as atividades desenvolvidas no projeto a algumas disciplinas, como Ciências, Geografia, Português, Artes, Matemática e Educação Física.

As atividades foram registradas em relatórios diários, que se somaram na construção de relatórios semestrais e do relatório final. Além das observações das variantes de cada encontro na escola, tais como pontos positivos, dificuldades e ocorrências, foram elaboradas questões avaliativas sobre o desempenho de cada participante no projeto, professores e estudantes da universidade, bem como professores, funcionários e alunos da escola rural.

\section{RESULTADOS E DISCUSSÃO}

Com o desenvolvimento dos trabalhos propostos, utilizamos diferentes instrumentos avaliativos (questionários, observação, caderno de campo, conversas informais), cujo objetivo foi obter uma triangulação de informações, na qual destacamos pontos positivos e negativos.

Na visão dos estudantes e professores universitários, os benefícios do estudo foram: (a) elaboração de conteúdos numa visão articulada com a educação ambiental; (b) desenvolvimento de atitude crítica para vencer desafios e criatividade para elaborar material didático alternativo e complementar; (c) uso de diferentes metodologias como suporte para a disseminação do conhecimento; (d) busca de ruptura com os métodos tradicionais de ensino; (e) motivação dos estudantes para serem agentes do seu processo de ensino-aprendizagem.

Os alunos da escola, bem como os professores e representantes da direção apontaram como pontos positivos: (a) a metodologia de estudo; (b) a alternância de propostas de aprendizagem: atividades teóricas e práticas; uso de figuras, desenhos, quadros, atlas anatômico, slides, peças cadavéricas; diagramar histórias; desenhar e colorir desenhos; atividades de teatro e recreativas, entre outras. Como principal fator negativo, foi referido o tempo de contato com os alunos, que poderia ter sido ampliado. Os professores da escola, que fizeram uso dos trabalhos desenvolvidos pelos alunos no projeto (redações, frases, desenhos, apresentação de teatro), avaliaram positivamente essa integração porque ela constituiu um fator de motivação e incentivo para as crianças.

Para todos os participantes, a vivência no projeto representou um grande desafio, por aliar o conhecimento de uma ciência básica como a Anatomia ao conhecimento ambiental num modelo de processo ensino-aprendizagem diferenciado.

Para compreender melhor o dinamismo histórico do ensino da Anatomia, percebemos a necessidade de traçar um retros- pecto do ensino da Anatomia Humana e suas diferentes vertentes nestes últimos tempos, estimulando um pensamento reflexivo sobre a circunstância atual. Não é possível descartar que o ensino desta disciplina, em vários momentos, se divida em aulas teóricas e práticas. Considerando o material bibliográfico examinado, foram encontradas diversas opções com propostas metodológicas específicas. Porém todos são unânimes em defender a Anatomia Humana como sendo a pedra angular do aprendizado dos profissionais da área de saúde. A aula prática é uma forma eficaz de oferecer contato direto com a realidade?

Para a abordagem do conteúdo teórico da Anatomia Humana, alguns pesquisadores educacionais defendem as aulas expositivas como a técnica de ensino mais coerente, ao passo que outros não abrem mão da eficiência das discussões em grupo, como reuniões tutoriais. Já um terceiro grupo sustenta o autoaprendizado como o melhor procedimento, isto é, no estudo individualizado, por meio de livros ou de materiais digitais fornecidos pela tecnologia de informatização, o educando pode delimitar suas aspirações e construir seu saber.

Na metodologia tradicional de ensino, a aula expositiva é, sem dúvida, uma das técnicas mais comuns e clássicas de instrução. Estas exposições têm boa qualidade, ou seja, constituem uma abordagem consistente, clara, coerente, sem deixar de ser motivadora ${ }^{3}$ É essencial que o professor exerça um papel relevante no processo de apropriação da cultura elaborada pelos estudantes. A originalidade de cada educando nasce de sua forma pessoal de assimilar e entender o mundo que o circunda, a partir de sua experiência de vida e da assimilação do conhecimento científico.

Nesta perspectiva, compreendemos a aula expositiva como sendo o ensinar pela palavra falada e que, como todos os meios de comunicação, abrange vertentes com vantagens e desvantagens. Uma respeitável vantagem é que, na exposição oral, é muito fácil ao comunicador imprimir seu entusiasmo sobre o tema, aumentando o interesse dos estudantes em aprender ${ }^{10}$.

Ocorre o contrário nas discussões em grupo, em que algumas pessoas se sentem intimidadas pela possibilidade de serem solicitadas a argumentar ou a comentar o assunto. Mas as discussões podem ser um poderoso acréscimo à exposição oral, fornecendo ao professor um feedback sobre o aprendizado dos estudantes. Geralmente, professores experientes alternam períodos de exposição oral para o ensino do conteúdo com momentos de discussão, avaliação do aprendizado e esclarecimento de dúvidas. Em todas as aulas se devem enfatizar pontos importantes e utilizar recursos visuais. Por outro lado, mesmo que se planeje uma aula expositiva satisfatória, este método apresenta limitações, como feedback vago, passividade dos ouvintes, não apreciação das diferenças individuais de 
habilidades e experiências, e a duração das aulas expositivas é inversamente proporcional ao interesse dos ouvintes ${ }^{10}$.

O ensino do conhecimento cognitivo da Anatomia Humana é tradicionalmente repassado pela exposição oral dos sistemas orgânicos e suas relações. Este procedimento, amplamente divulgado e aplicado, certamente se fundamenta nas vantagens citadas, mas traz consigo o conjunto de desvantagens de um relacionamento unidirecional entre professor e estudante.

Após décadas de aceitação desta técnica de ensino sem questionamentos quanto a sua eficácia, algumas dificuldades encontradas estimularam filósofos e educadores a repensar a prática pedagógica na área da educação médica, refletindo sobre a melhor maneira de ensinar Anatomia como uma ciência primordial em vários aspectos, como o desenvolvimento de habilidades clínicas e a concepção biomédica de saúde/doença.

Como foi possível constatar no desenvolvimento deste trabalho, a necessidade de reflexão e de proposição de novos rumos é um ponto de partida para aprimorar a formação de profissionais da área da saúde, muitos dos quais concomitantemente exercerão o papel de professores em suas áreas específicas. O caminho aberto pela necessidade de reflexões sobre o modelo de formação docente propõe uma série de intervenções que torna possível, em nível teórico e prático, um novo modo de formar professores ${ }^{11}$.

Não é prudente se ater a práticas pedagógicas rotineiras, estereotipadas, muitas vezes alicerçadas em ideários simplificados, quase clichês, que perderam o potencial para a análise crítica da realidade e o enfrentamento dos problemas educacionais $^{12}$. A elaboração do planejamento pedagógico deve anteceder quaisquer alterações no desenho curricular.

Entre os diversos fatores que afetam a implementação de mudanças no campo educacional, é necessário assinalar a importância de expor a necessidade e a relevância da transformação pretendida, a clareza dos objetivos, a complexidade, a qualidade e a praticidade da proposta de reformulação ${ }^{13}$. O pesquisador garante o papel do coordenador, o relacionamento entre os professores e o grau de cooperação existente entre eles como fatores que contribuem para o sucesso ou o fracasso das reformulações curriculares.

Este pensamento suscita a importância de edificar um arcabouço centrado no diálogo entre o professor e o estudante, tornando viável um planejamento coletivo, que deve incluir um processo contínuo de reflexão e autoavaliação. A reflexão permite analisar os acontecimentos e construir saberes que cobrem situações comparáveis, que podem ocorrer em lugares diferentes ${ }^{14}$.

Para construir um planejamento reflexivo e crítico, o caminho mais sensato a transpor é a contextualização, isto é, apreciar e interpretar a realidade que nos cerca. Também é ne- cessário ser flexível, estar disposto a alterar ações previstas, mas sem descaracterizar a proposta inicial de trabalho. É fundamental elucidar os objetivos e conhecer os recursos a serem empregados no seu desenvolvimento. Ao longo do processo e ao final, é importante avaliar o desempenho dos participantes no contexto de sala de aula.

Diante das considerações apresentadas, é possível observar o surgir de um esqueleto conceitual para o emprego de novas propostas metodológicas no processo de ensino. Esta estrutura pode ser enriquecida pelo uso da tecnologia educacional, por meio de instrumentos que podem dinamizar a aprendizagem, particularmente da Anatomia Humana. Todas as questões abordadas devem ser objeto de análise do processo de formação dos futuros profissionais da área da saúde.

Para além de manter seu espaço, a Anatomia Humana necessita expandir sua potencialidade nas reformas curriculares dos cursos da área da saúde, adquirindo um reconhecimento frente à metodologia baseada em problemas e ao aprendizado fundamentado em habilidades clínicas, como parte integrante do currículo que solidifica o desenvolvimento e a retenção do conhecimento clínico e sua prática. Para tanto, a informação anatômica deve ser apresentada num contexto apropriado, e não mais como um conhecimento puro ${ }^{15}$.

A defesa da abordagem sobre a relevância dessa ciência básica inserida na integralidade curricular ocorre mesmo diante do lamento pelo velho fetiche de descrições minuciosas de origens e inserções musculares, frisando aspectos que deveriam ser adiados, para dar maior atenção à Anatomia Clínica e Regional e às admiráveis relações entre órgãos ${ }^{16}$. Os estudantes precisam ser instigados a se instruir de maneira a alcançar um profundo aprendizado, sendo responsáveis pelo próprio desenvolvimento, com pesquisas e suporte apropriado.

O significativo valor da ciência básica em foco reside no fato de que todos aqueles que cuidam de pacientes devem dominar os conhecimentos da estrutura anatômica do corpo humano e, isso não ser restrito aos cirurgiões ${ }^{16}$. Cabe ressaltar que estatísticas alarmantes sugerem o aumento do número de estudantes nos cursos de Medicina associado à diminuição do número de professores de Anatomia contratados pelas instituições de ensino, o que deve ser avaliado cuidadosamente.

Ao mesmo tempo, há um alerta para o fato de que as peças cadavéricas estão sendo substituídas gradativamente por bonecos e imagens radiológicas, tecnologias que deveriam substancialmente contribuir com o aprendizado da Anatomia Humana ${ }^{17}$. Esse fato tem sido confirmado por especialistas em radiologia que costumam voltar ao laboratório de peças cadavéricas para uma revisão de conteúdos e entender a nova ciência apresentada em filmes. 
O significativo valor da ciência básica reside no fato de que todos aqueles que cuidam de pacientes devem dominar os conhecimentos da estrutura anatômica do corpo humano, e isto não se restringe aos cirurgiões ${ }^{14}$. Estatísticas alarmantes indicam o aumento do número de estudantes nos cursos de Medicina associado à diminuição do número de professores de Anatomia contratados pelas instituições de ensino, o que deve ser avaliado cuidadosamente.

Ao mesmo tempo, há um alerta para o fato de que as peças cadavéricas estão sendo substituídas gradativamente por bonecos e imagens radiológicas, tecnologias que deveriam contribuir de forma substancial para o aprendizado da Anatomia Humana ${ }^{14}$. Esse fato tem sido confirmado por especialistas em radiologia que costumam voltar ao laboratório de peças cadavéricas para revisar conteúdos e entender a nova ciência apresentada em filmes.

Para abarcar a questão das técnicas de ensino do conteúdo teórico anatômico de forma globalizada, não podemos desconsiderar os grandes avanços tecnológicos na área da informática, que promovem melhor desempenho no estudo individual. A inserção da informatização em ambiente acadêmico promove uma ampla modificação nas maneiras de aprender, visto que amplia grandemente as estratégias de ensino que podem ser requeridas pelos professores.

Os estudantes consideram útil a incorporação de computadores ao processo de autoaprendizagem porque tal medida facilita a compreensão dos assuntos, particularmente os complexos. O uso de programas de informática se converteu num importante e diário apoio em todo o processo de ensino, além de resultar numa motivação adicional no estudo tradicional da Anatomia Humana ${ }^{18}$.

Neste contexto, a multimídia tem grande potencial de utilização na educação à distância, por meio de transmissão via satélite, videoconferência e internet, particularmente na autoaprendizagem. Trata-se de uma alternativa criativa para as pessoas que desejam permanecer atualizadas, estimuladas a buscar oportunidades futuras de emprego ${ }^{19}$. Seguindo esta tendência, o setor de desenvolvimento de softwares voltados à educação tem crescido de maneira considerável, fato aliado à diminuição dos custos para se adquirir um microcomputador.

O autoaprendizado da Anatomia Humana pode ser grandemente facilitado com o auxílio de sistemas multimídia em CD-ROM ${ }^{20}$. Na Universidade Estadual de Londrina, o Departamento de Anatomia teve o privilégio de participar da elaboração do Locomoshow - Atlas Anatômico do Aparelho Locomotor Humano - , que auxilia a dinâmica do autoaprendizado, além de contribuir para as discussões em grupo.

No intuito de compreender a dimensão desta ciência básica, a Anatomia Humana, é essencial vislumbrá-la por outro ângulo: sua aplicação na prática de laboratório com peças cadavéricas formolizadas, previamente preparadas ou estágios de dissecação. Sem isto, seu aprendizado seria deficiente. Desta maneira, procuramos respostas na abordagem de diferentes estratégias de ensino para as aulas práticas desta disciplina.

Uma pesquisa em que foram entrevistados 727 estudantes, por meio de um formulário com respostas voluntárias e anônimas, trouxe excelentes contribuições. $\mathrm{O}$ assunto pesquisado foi dividido em tópicos: prática, material didático, qualidade docente, exames, organização, outros. As respostas mais frequentes dos estudantes (26\%) se referiram à necessidade de incrementar as aulas práticas com maior quantidade de horas dedicadas aos trabalhos práticos com cadáveres e uso de melhor material didático, com menor quantidade de discentes orientados por determinado número de docentes ${ }^{21}$.

Os anatomistas em geral defendem a necessidade da aula prática para o aprendizado em Anatomia. Historicamente, não há dúvida quanto a este fato $^{22}$, pois isto é verdade hoje como em qualquer época do passado. Além de ser relatada como uma descoberta muito excitante para o aprendizado pela maioria dos estudantes, a dissecação contribui para o ensino do convívio com a morte já no início do curso de Medicina, ajudando aqueles mais sensíveis a enfrentar de forma mais aberta esse problema ${ }^{23}$.

Recentemente, o exercício da dissecação como parte do currículo tem acendido discussões, e muitos são seus benefícios nas aulas práticas de Anatomia. Entre estes, alguns são identificados pelos próprios estudantes: desenvolvimento de trabalho em equipe, respeito pelo corpo, familiarização com o corpo, aplicação das habilidades práticas, integração entre teoria e prática, preparação para o trabalho clínico ${ }^{24}$.

Alguns pesquisadores citam a dificuldade de aquisição de peças cadavéricas como um grande empecilho para esta técnica de aprendizado, já que este processo se torna cada vez mais complexo. Este fato conduz à hipertrofia de instituições médicas que são contundentes em defender o ensino da Anatomia sem a utilização de peças cadavéricas, como a UK Medical School, onde os estudantes aprendem Anatomia por autópsia de órgãos patológicos e por meio de treinamento prático cirúrgico durante o curso de pós-graduação ${ }^{25}$. Os pesquisadores acreditam que, no transcorrer do desenvolvimento desse programa implantado na UK Medical School, surgirão fortes evidências da eficiência do ensino da Anatomia Humana sem o emprego de peças cadavéricas como estratégia de ensino. Enquanto isso, consideram importante o debate contínuo sobre a questão, pois afirmam que vários autores concluíram apenas virtualmente que o uso do cadáver seria fundamental ao ensino médico. 
Para integrar o ensino teórico e prático da Anatomia Humana, métodos e técnicas pedagógicas têm sido propostos na tentativa de adequar o ensino à realidade atual, considerando novas estratégias e agilizando os procedimentos laboratoriais. A percepção dos estudantes é a de que a docência atualizada e fundamentada em tecnologia de informatização não coloca de lado os métodos tradicionais da prática pedagógica, ou seja, eles continuam a dizer que consideram essenciais as aulas tradicionais com prática de dissecação ${ }^{18}$.

Auxiliando o autoaprendizado, os computadores se tornarão cada vez mais importantes no ensino da Anatomia. Essas máquinas facilitam, por exemplo, certos aspectos da instrução, como a animação de desenvolvimento de processos, e também podem servir como um atlas anatômico, ou seja, ser um subsídio às aulas. Porém a dissecação, associada a uma relação tradicional entre professor e estudante, é o melhor modo de desenvolver a habilidade para solucionar problemas clínicos ${ }^{26}$.

Este estudo proporcionou a análise de variáveis imprescindíveis para motivar e envolver todos os participantes do processo ensino-aprendizagem no objetivo de apreensão do conhecimento de cada conteúdo proposto. Trata-se de construir conhecimento com a escola, pensando numa formação considerada como uma relação de provoca-ação com o outro, em seu sentido formativo ${ }^{27}$.

Diante da variação pedagógica que envolve a prática docente relacionada ao Departamento de Anatomia, somos instigados a sugerir uma nova proposta pedagógica, baseada na inserção social do estudante envolvido em uma abordagem multiprofissional. Contudo, temos que frisar que toda possibilidade de mudança gera conflitos e é necessário reconhecer que obstáculos terão que ser transpostos.

\section{CONCLUSÃO}

Vemos a urgente necessidade de suscitar discussões e reflexões sobre a prática pedagógica, já que muitos educadores têm buscado novas alternativas para proporcionar um ensino coerente com as mudanças da sociedade, e dúvidas têm pairado no ar. Devemos caminhar no sentido de ampliar as opções na educação, sem perder de vista o objetivo final de oferecer ao estudante a chance de construir o seu saber de forma digna e comprometida com as condições de vida e saúde da população.

Desta forma, estaremos contribuindo para a melhoria da qualidade do processo de aprendizagem dos futuros profissionais da saúde a partir das reflexões sobre o ensino da Anatomia no contexto atual; além de incitar avaliações de práticas docentes quanto à utilização de recursos tecnológicos pelo profissional da educação no ensino superior, estudar a ques- tão da inserção das metodologias inovadoras no processo de ensino-aprendizagem e propiciar alternativas para integrar e dinamizar as aulas de Anatomia Humana.

O ensino da ciência básica é essencial para possibilitar a compreensão do conteúdo necessário ao alcance de objetivos práticos no processo de aprendizagem. Desta maneira, deve haver o reconhecimento e suporte às pesquisas na área educacional que pretendem criar um ambiente onde ideias são compartilhadas desde o laboratório de ciências até a aplicação prática e que conduzam a uma exploração cuidadosa e sistemática dos múltiplos fatores de variabilidade, direcionando testes e elaborando teorias ${ }^{28}$.

Infelizmente, as discussões específicas sobre o ensino em Anatomia, em geral, são pouco comuns. Diante desta realidade e considerando este tema de suma importância para a revitalização das práticas pedagógicas predominantes no ensino das profissões de saúde, optou-se por este projeto de extensão, no qual os estudantes foram inseridos precocemente no contexto social.

Neste projeto foi possível avaliar diferentes possibilidades de articular atividades educativas e recreativas, integrando conhecimentos afins, numa forma concreta de estimular o diálogo entre ciências, e oportunizando aplicar diferentes metodologias no ensino da Anatomia. Consideramos a avaliação um instrumento de melhoria e aperfeiçoamento para a continuidade de projetos dessa natureza.

Em algumas circunstâncias, dependendo de uma mudança cultural de docentes e instituições de ensino, é preciso viabilizar modificações significativas, tais como: disponibilidade de peças cadavéricas em melhor estado de conservação; associação de peças com o uso de bonecos; metodologias pedagógicas que estimulem comportamentos de ética e de visão crítica dos estudantes - ou seja, deve haver um somatório dos instrumentos disponíveis ao trabalho em busca de melhor apreensão dos conteúdos.

Acima de tudo, o bom senso leva a pensar que a formação educacional se elabora por meio de um trabalho de flexibilidade crítica e de uma construção contínua de identidade entre professor e estudantes. Somente o convívio diário com as dificuldades da prática docente e discente pode originar alternativas adequadas ao aprimoramento do processo ensinoaprendizagem vivenciado na realidade social de nosso país, com características regionais específicas.

\section{REFERÊNCIAS}

1. Fornaziero CC, GIL CR. Novas tecnologias aplicadas ao Ensino da Anatomia Humana. Rev. Bras Educ Med. 2003;27(1):141-6. 
2. Mamede S. Aprendizagem baseada em problemas. Anatomia de uma nova abordagem educacional. Fortaleza: $\mathrm{Hu}-$ citec; 2001.

3. Luckesi CC. Filosofia da Educação. São Paulo: Cortez; 1994.

4. Torres J. El curriculum oculto. Madrid: Morata; 1991.

5. Dias AMI. O que são processos pedagógicos? Rev Educ AEC. 2004;33:31-41.

6. Manata DV. Planejamento Docente, questão didática. Rev Educ AEC. 2004;33:7-19.

7. Clough RW, Lehr R. Testing knowledge of human gross anatomy in medical school: an applied contextual-learning theory method. Clin. Anat. 1996;9(4):263-8.

8. Casady RL, Hillman JR. The relevancy of Anatomy and other Basic Sciences to the Practice of Medicine. J Med Educ. 1977; 52:210-1.

9. Bordenave JD. Estratégias de ensino-aprendizagem. 28aed. Rio de Janeiro: Vozes; 2007.

10. Teixeira G. A aula expositive e o método de. [S.1.:s.n.]; 2005. [Tradução adaptada do artigo : The Lecture and Discussion Method for Management Education: Pros and Cons de Griffin R, Cashin W. publicado no Journal of Management Development 1989; 8: 25-32.

11. Costa NMSC. Docência no ensino médico: por que é tão difícil mudar? Rev Bras Educ Med. 2007;31(1):21-30.

12. Basso IS. Significado e sentido do trabalho docente. Cad. CEDES. 1998;44:19-30.

13. Pinar WF. Understanding curriculum: An Introduction to the Study of Historical and Contemporary Curriculum Discourses. In: Pinar W, Taubman PM, Reynolds WM, Slattery, P. Understanding curriculum. New York: Peter Lang Publishing; 1995. p. 3-45.

14. Perrenoud P. Formar professores em contextos sociais em mudança: prática reflexiva e participação crítica. Rev Bras Educ Med. 1999;12:5-21.

15. Dangerfield P, Bradley P, Gibbs T. Learning gross anatomy in a clinical skills course. Clin. Anat. 2000;13:444-7.

16. Wong WC, Tay SS. The teaching of Anatomy: the first hundred years (1905-2005). Ann. Acad. Med. Singapore. 2005;34:72C-78C.

17. Older J. A must for teaching the next generation. Surgeon. 2004;2:303-4.

18. Guiraldes del Canto H, Oddó Atria H, Ortega F X, Oyarzo MP. Metodos computacionales y gráficos de apoyo al aprendizaje de la anatomia humana: vision de los estudiantes. Rev Chil Anat. 1995; 13(1):67-71.

19. Dawes BS, Gregory RN. Can distance learning provide a twenty - first century hallmark? AORN J. 1998; 68(2): 1702,174 .
20. Araujo JC, Fornaziero CC, Omoto MHH, Yoshida M. Inovações tecnológicas no ensino da Anatomia Humana. Braz J. Morphol. Sci. 2000; 17:220-37.

21. Barrovecchio JC, Perez B, Paz LBL. Sugerencias acerca del proceso de enseñanza-aprendizaje en anatomia humana. Rev Chil Anat. 1998;16:219-24.

22. Jones DG. Reassessing the importance of dissection: a critique and elaboration. Clin Anat. 1997;10:123-7.

23. Marks SC, Bertman SL, Penney J. Human Anatomy: a foundation for education about death and dying in medicine. Clin Anat. 1997;10:118-22.

24. Lempp HK. Perceptions of dissection by students in one medical school: beyond learning about Anatomy. A qualitative study. Med Educ. 2005;39:318-25.

25. Mclachlan JC, Bligh J, Bradley P, Searle J. Theaching Anatomy without cadavers. Med Educ. 2004;38:418-24.

26. Cahill DR, Leonard R J. The role of computers and dissection in teaching anatomy: a comment. Clin Anat. 1997;10:140-1.

27. Chaluh Laura Noemi. Professora e pesquisadora: um encontro na sala de aula. Pro-Posições 2009;20(1):225-39.

28. -Norman GR, Schmidt H. Effectiveness of problem-based learning curricula: theory, practice and paper darts (problem-based learning). Med Educ. 2000;34:721-8.

\section{CONTRIBUIÇÃO DOS AUTORES}

Célia Cristina Fornaziero participou do desenvolvimento deste projeto de extensão da UEL, da análise e interpretação dos dados, e da redação do texto. Pedro Alejandro Gordan participou deste projeto, do levantamento bibliográfico, da análise metodológica e da redação deste texto. Maria Aparecida V. de Carvalho foi autora da concepção e desenho deste projeto de extensão da UEL, participou da análise e interpretação dos dados assim como da redação deste texto. José Carlos Araújo participou deste projeto como coordenador das atividades e da análise e interpretação dos dados. Juarez Cezar Borges de Aquino participou de forma ativa neste projeto de extensão da UEL como orientador dos alunos, e da interpretação dos dados.

\section{CONFLITO DE INTERESSES}

Declarou não haver.

\section{ENDEREÇO PARA CORRESPONDÊNCIA}

Célia Cristina Fornaziero

Rua Roberto Júlio Roehrig, 105

Jardim Mediterrâneo - Londrina

CEP 86047-090 - PR

E-mail: celiafornaziero@uel.br 